\title{
DYNAMICS OF RECTANGULAR ORTHOTROPIC PLATES USING CHARACTERISTIC ORTHOGONAL POLYNOMIAL - GALERKIN'S METHODS
}

\author{
N. N. Osadebe ${ }^{1}$, C. M. Attama2,", O. A. Oguaghamba ${ }^{3}$ \\ 1,2,3 Department of Civil EngineERING, University of Nigeria, NSUKKA. ENUGU STATe, NIGERIA \\ E-mail addresses:1'mkemamaka@yahoo.com,2chuka.attama@unn.edu.ng, \\ 3 onyedikachi.oguaghamba@unn.edu.ng
}

\begin{abstract}
The assumed deflection shapes used in the approximate methods such as in the Galerkin's method were normally formulated by inspection and sometimes by trial and error, until recently, when a systematic method of constructing such a function in the form of Characteristic Orthogonal Polynomial (COPs) was developed by Bhat in 1985. In the vibrational analyses of orthotropic rectangular plates with different boundary conditions, the study used the characteristic orthogonal polynomial theory to obtain satisfactory approximate shape functions for these plates. These functions were applied to Galerkin indirect varational method to obtain new set of fundamental natural frequencies for these plates. The results were reasonable when compared with those in the previous work. All round simply supported thin rectangular plate (SSSS), rectangular clamped plated (CCCC) and rectangular plate with one edge clamped and all others edges simply supported (CSSS) gave 5.172, 9.429 and 6.202 natural frequencies in rad $/ \mathrm{sec}$ respectively at $0.05 \%, 0.0 \%$ and $22.93 \%$ difference with the previous[3] results5.170 rad/sec, 9.429rad/sec and 8.048rad/sec for SSSS, CCCC and CSSS. For others like: rectangular plate with one edge simply supported and all other edges clamped (CCSC), rectangular plate simply supported at two opposite sides and clamped at the others (CSCS) and rectangular plate clamped at two adjacent sides and simply supported at the others (CCSS) with no available results, their natural frequencies obtained are 8.041rad/sec, $6.272 \mathrm{rad} / \mathrm{sec}$ and 7.106rad/sec respectively.
\end{abstract}

Keywords: Fundamental natural frequency, Free Vibration, Reinforced Concrete Slab, Characteristic Orthogonal Polynomial

\section{INTRODUCTION}

In recent years, lightweight structures have been widely used in many engineering fields, and hence vibration analysis of differently shaped plates has been studied extensively owing to its practical applications. The applications of composite materials in engineering structures require information about the vibration characteristics of anisotropic materials. The free vibration of orthotropic plates is an important area of such behaviour. Orthotropic materials have extensive application in the modern technology, such as in modern missiles, spacecrafts, nuclear reactors, and printed circuit boards. Their high strength along with small specific mass make the composite materials ideal for applications in spacecrafts, vehicle systems, nuclear reactors, etc. Most of the applications subject the composite materials to dynamic loading. It is known that the orthotropic materials exhibit a different dynamic response when compared with that of similar isotropic structures.
Man, equipment and facilities including various types of machines (technological loads) are the source of impact and dynamic loads. Wind and earthquake loads are not to be mentioned here, but it should be noted that even weak wind pressures could be the excitor to facilities and indirectly make unpleasant noises and vibrations [1].

The analysis of structural vibration is necessary in order to calculate the natural frequencies of a structure, and the response to the expected excitation. In this way it can be determined whether a particular structure will fulfill its intended function and, in addition, the results of the dynamic loadings acting on a structure can be predicted, such as the dynamic stresses, fatigue life and noise levels. Hence the integrity and usefulness of a structure can be maximized and maintained. Reinforced concrete slabs, exhibit force due to mass of inertia; thus, they are susceptible to free vibration. 


\section{BACKGROUND OF STUDY}

Euler [2] performed a free vibration analysis of plate problems and indicated the first impetus to a mathematical statement of plate problems. The governing equation for a thin rectangular plate subjected to direct compressive forces $\mathrm{N}_{\mathrm{x}}$, was derived by Navier [3].

Thompson and Dahleh [4] noted that all systems possessing mass and elasticity are capable of free vibration, or vibration that takes place in the absence of external excitation.

Xiang et al [5] used the two -dimensional polynomials as the admissible functions to study the vibrations of rectangular Mindlin plates with elastic edge supports by the Ritz method and the same problems were investigated by Gorman [6] using the superposition method.

Malaikah et al [7] investigated the effect of the embedded steel bars in the concrete cylinders on the dynamic modulus of concrete. Their work revealed that the presence of the single bar made the specimen less susceptible to micro cracking.

Leissa [8] presented analytic solutions of natural frequencies of the various types of plates and the corresponding mode shapes based on trigonometric functions.

Structural engineers have long been trying to develop solutions using the full potential of composing materials [9]. These have been the structural solution progress directly towards increase in materials science knowledge. Thus, the constituent materials of reinforced concrete slabs (and in this case rectangular plates) using characteristic orthogonal polynomial of various shape functions would not bean exception in predicting the dynamic regime of structural elements. It is therefore believed herein that investigating this will suggest a safe, economical and aesthetic reinforced concrete slab design. Before, the analysis for natural frequency of thin rectangular plate (reinforced concrete slabs) taking into account of the shape functions has been verified; thus making work in this regard demanding.

\subsection{Dynamic Equation for Orthotropic Plates Using Galerkin's Method}

The governing differential equation for free motion of orthotropic plates are given in Equation (1) as in [3]:

$$
\mathrm{D}_{\mathrm{x}} \frac{\partial^{4} \mathrm{w}}{\partial \mathrm{x}^{4}}+2 \mathrm{H} \frac{\partial^{4} \mathrm{w}}{\partial \mathrm{x}^{2} \partial \mathrm{y}^{2}}+\mathrm{D}_{\mathrm{y}} \frac{\partial^{4} \mathrm{w}}{\partial \mathrm{y}^{4}}=\rho \mathrm{h} \omega^{2}[\mathrm{~W}(\mathrm{x}, \mathrm{y})]
$$

The flexural rigidities of orthotropic plates (two way reinforced slabs) are given as [3]:

$$
\mathrm{D}_{\mathrm{x}}=\frac{\mathrm{E}_{\mathrm{c}}}{\left(1-\mu_{\mathrm{c}}^{2}\right)}\left[\frac{\mathrm{h}^{3}}{12}-\mathrm{I}_{\mathrm{xs}}+\frac{\mathrm{E}_{\mathrm{s}}}{\mathrm{E}_{\mathrm{c}}} \mathrm{I}_{\mathrm{xs}}\right]
$$

$$
\begin{gathered}
D_{y}=\frac{E_{c}}{\left(1-\mu_{c}^{2}\right)}\left[\frac{h^{3}}{12}-I_{y s}+\frac{E_{s}}{E_{c}} I_{y s}\right] \\
D_{s}=\frac{1-\mu_{c}}{2} \sqrt{D_{x} D_{y}} \\
H=\sqrt{D_{x} D_{y}} \\
D_{x y}=\mu_{c} \sqrt{D_{x} D_{y}}
\end{gathered}
$$

In (1) to (6), and $\mu_{c}$ are modulus of elasticity and Poisson's ratio for concrete, respectively. $E_{s}$ is the modulus of elasticity for steel; and $I_{x s}, I_{y s}$ are the moments of inertia of steel bars about the $\mathrm{x}$ and $\mathrm{y}$ axes, respectively. Then Galerkin equation was given as [3]:

$$
\iint_{\mathrm{A}}^{\mathrm{g}}\left[\mathrm{D}_{\mathrm{x}} \frac{\partial^{4} \mathrm{w}}{\partial \mathrm{x}^{4}}+2 \mathrm{H} \frac{\partial^{4} \mathrm{w}}{\partial \mathrm{x}^{2} \partial \mathrm{y}^{2}}+\mathrm{D}_{\mathrm{y}} \frac{\partial^{4} \mathrm{w}}{\partial \mathrm{y}^{4}}-\mathrm{P}\right] \mathrm{f}_{\mathrm{i}}(\mathrm{x}, \mathrm{y}) \mathrm{dxdy}=0
$$

Where, $w=w(x, y)$ is an unknown, $P$ is a given load term defined also in the domain,$D^{* *}$ is the Flexural rigidity of orthotropic plates. For free vibration, the external exciting force $\mathrm{P}=0$. In the dynamic regime, the forcing function of the governing differential equation becomes [3]:

$$
\mathrm{P}=\mathrm{P}(\mathrm{x}, \mathrm{y}, \mathrm{t}) \rho \mathrm{hh} \frac{\partial^{2} \mathrm{w}}{\partial \mathrm{t}^{2}}(\mathrm{x}, \mathrm{y}, \mathrm{t}) \ldots
$$

Thus, the differential Equation (7) becomes,

$$
\begin{aligned}
& \iint_{A}^{g}\left[D_{x} \frac{\partial^{4} w}{\partial x^{4}}+2 H\right.\left.\frac{\partial^{4} w}{\partial x^{2} \partial y^{2}}+D_{y} \frac{\partial^{4} w}{\partial y^{4}}\right] f_{i}(x, y) d x d y \\
&=\iint_{A}^{g}[P(x, y, t) \\
&\left.+\rho h \omega^{2}[W(x, y)]\right] f_{i}(x, y) d x d y
\end{aligned}
$$

Equation (9) is the differential equation of forced, undamped motion of plate. Thus, for natural or free vibrations, $\mathrm{P}(\mathrm{x}, \mathrm{y}, \mathrm{t})$ is set equal to zero, and equation (9) becomes:

$$
\begin{aligned}
& \iint_{A}^{g}\left(D_{x} \frac{\partial^{4} w}{\partial x^{4}}+2 H \frac{\partial^{4} w}{\partial x^{2} \partial y^{2}}+D_{y} \frac{\partial^{4} w}{\partial y^{4}}\right) f_{i}(x, y) d x \\
& =\iint_{A}^{g} \rho h \omega^{2}[W(x, y)] f_{i}(x, y) d x d y
\end{aligned}
$$

In non dimensional form, $\mathrm{x}=\mathrm{aR}, \mathrm{y}=\mathrm{bQ}$, then: $\omega^{2}$

$$
=\frac{\iint_{A}^{g}\left(D_{x} \frac{\partial^{4} w}{a^{4} \partial R^{4}}+2 H \frac{\partial^{4} w}{a^{2} b^{2} \partial R^{2} \partial Q^{2}}+D_{y} \frac{\partial^{4} w}{b^{4} \partial Q^{4}}\right) \bar{W} d R d Q}{\iint_{A}^{g} \rho h[W(R, Q)] \bar{W} d R d Q}
$$

Equation (11) is the Galerkin's natural frequency of orthotropic rectangular plate.

Note: Deflection, w, must satisfy the boundary conditions at the plate edge (these conditions practically do not differ from those in the case of static equilibrium) and the initial conditions given in section 3 [3]:

\section{METHODOLOGY}

\subsection{Characteristic Orthogonal Polynomial Shape Function}

Consider a rectangular plate of dimension a along $\mathrm{x}$ and $\mathrm{b}$ along $y$, then uniform. If the deflection pattern of the 
plate along $\mathrm{x}$ is represented by a beam strip qualitatively, the beam function along $\mathrm{x}$ is taken as $\mathrm{f}(\mathrm{x})$ and along $\mathrm{y}$ as $\mathrm{g}$ (y). The solution for a prismatic beam of constant EI and length spanning along $\mathrm{x}$ is [11].

$$
w_{x}=F(x)=\sum_{m=1}^{\infty} X_{m} x^{m}
$$

and along y as

$$
\mathrm{w}_{\mathrm{y}}=\mathrm{G}(\mathrm{y})=\sum_{\mathrm{n}=1}^{\infty} \mathrm{Y}_{\mathrm{n}} \mathrm{y}^{\mathrm{n}}
$$

In (13) and (14), $X_{m}$ and $Y_{n}$ are constant parameters in $x$ and $\mathrm{y}$ directions respectively. $\mathrm{m}$ and $\mathrm{n}$ are series to infinity limit. Thus, the displacement function for the rectangular plate is therefore assumed as a product of two functions; one of which is a pure function of $\mathrm{x}$ and the other is of $y$, so that:

$$
\begin{aligned}
& \mathrm{w}(\mathrm{x}, \mathrm{y})=\mathrm{F}(\mathrm{x}) \cdot \mathrm{G}(\mathrm{y})=\mathrm{w}_{\mathrm{x}} \cdot \mathrm{w}_{\mathrm{y}} \\
& w_{x}=F(x)=\sum_{m}^{\infty} \sum_{\mathrm{n}}^{\infty} X_{m} x^{m} Y_{\mathrm{n}} \mathrm{y}^{\mathrm{n}}
\end{aligned}
$$

Expressing Equations (12), (13), (14) and (15) in the form of non-dimensional parameters, say $R$ and $Q$ for $x$ and y directions respectively:

$$
\mathrm{x}=\mathrm{aR} \quad \text { and } \mathrm{y}=\mathrm{bQ}
$$

Then, Equations (12),(13) and (15) become:

$$
\begin{gathered}
w_{x}=F(\mathrm{R})=\sum_{m=1}^{\infty} X_{m} \mathrm{a}^{\mathrm{m}} \mathrm{R}^{m} \\
\mathrm{w}_{\mathrm{y}}=\mathrm{G}(\mathrm{Q})=\sum_{\mathrm{n}=1}^{\infty} \mathrm{Y}_{\mathrm{n}} \mathrm{b}^{\mathrm{n}} \mathrm{Q}^{\mathrm{n}}
\end{gathered}
$$

Let:

$$
\begin{gathered}
A_{m}=X_{m} \mathrm{a}^{\mathrm{m}} \\
B_{n}=Y_{n} \mathrm{~b}^{\mathrm{n}} \\
w_{x}=F(\mathrm{R})=\sum_{m=1}^{\infty} A_{m} \mathrm{R}^{m} \\
\mathrm{w}_{\mathrm{y}}=\mathrm{G}(\mathrm{Q})=\sum_{\mathrm{n}=1}^{\infty} \mathrm{B}_{\mathrm{n}} \mathrm{Q}^{\mathrm{n}}
\end{gathered}
$$

Also,

$$
\mathrm{w}(\mathrm{R}, \mathrm{Q})=\sum_{\mathrm{m}=1}^{\infty} \sum_{n=1}^{\infty} A_{m} \mathrm{~B}_{\mathrm{n}} \mathrm{R}^{m} \mathrm{Q}^{\mathrm{n}}
$$

Since Equation (11), which is orthotropic plate's equation in free vibration regime is a fourth order differential and the density of the plate is constant, then, the value of $m$ and $n$ in Equation (23) must be equal to 4 . Expanding Equation (21), (22) and (23) to $4^{\text {th }}$ series we obtain:

$$
\begin{array}{r}
w_{x}=F(\mathrm{R})=\sum_{m=1}^{4} A_{m} \mathrm{R}^{m} \\
=\left(\mathrm{A}_{0}+\mathrm{A}_{1} \mathrm{R}+\mathrm{A}_{2} \mathrm{R}^{2}+\mathrm{A}_{3} \mathrm{R}^{3}+\mathrm{A}_{4} \mathrm{R}^{4}\right) \\
\mathrm{w}_{\mathrm{y}}=\mathrm{G}(\mathrm{Q})=\sum_{\mathrm{n}=1}^{\infty} \mathrm{B}_{\mathrm{n}} \mathrm{Q}^{\mathrm{n}}
\end{array}
$$

$$
\begin{gathered}
=\left(\mathrm{B}_{0}+\mathrm{B}_{1} \mathrm{Q}+\mathrm{B}_{2} \mathrm{Q}^{2}+\mathrm{B}_{3} \mathrm{Q}^{3}+\mathrm{B}_{4} \mathrm{Q}^{4}\right) \\
\mathrm{w}(\mathrm{R}, \mathrm{Q})=\sum_{\mathrm{m}=1}^{\infty} \sum_{n=1}^{\infty} A_{m} \mathrm{~B}_{\mathrm{n}} \mathrm{R}^{m} \mathrm{Q}^{\mathrm{n}}=F(\mathrm{R}) \cdot \mathrm{G}(\mathrm{Q}) \\
=\left(\mathrm{A}_{0}+\mathrm{A}_{1} \mathrm{R}+\mathrm{A}_{2} \mathrm{R}^{2}+\mathrm{A}_{3} \mathrm{R}^{3}+\mathrm{A}_{4} \mathrm{R}^{4}\right)\left(\mathrm{B}_{0}+\mathrm{B}_{1} \mathrm{Q}\right. \\
\left.\quad+\mathrm{B}_{2} \mathrm{Q}^{2}+\mathrm{B}_{3} \mathrm{Q}^{3}+\mathrm{B}_{4} \mathrm{Q}^{4}\right)
\end{gathered}
$$

Equation (26) is a 25 terms equation to maximum power of 8 with several unknowns. The coefficients $A_{m}$ and $B_{n}$ of the series are determined from the boundary conditions at the edges of the plate. For the beams, the moment along $\mathrm{x}$ and $\mathrm{y}$ directions are given as [12]:

$$
\begin{array}{r}
M_{x}=\frac{-D \partial^{2} w}{\partial x^{2}} \\
M_{y}=\frac{-D \partial^{2} w}{\partial y^{2}}
\end{array}
$$

Expressing (27) and (28) in terms ofR and $Q$ we obtain:

$$
\begin{gathered}
\mathrm{M}_{\mathrm{x}}=\frac{-\mathrm{D} \partial^{2} \mathrm{w}}{\mathrm{a}^{2} \partial \mathrm{R}^{2}} \\
\mathrm{M}_{\mathrm{x}}=\frac{\partial^{2}}{\partial \mathrm{R}^{2}}\left(A_{0}+A_{1} \mathrm{R}+A_{2} \mathrm{R}^{2}+A_{3} \mathrm{R}^{3}+A_{4} \mathrm{R}^{4}\right) \frac{-\mathrm{D}}{\mathrm{a}^{2}} \\
\text { Thus, } \quad \mathrm{M}_{\mathrm{x}}=\left(2 A_{2}+6 A_{3} \mathrm{R}+12 A_{4} \mathrm{R}^{2}\right) \frac{-\mathrm{D}}{\mathrm{a}^{2}} \\
\mathrm{M}_{\mathrm{y}}=\frac{-\mathrm{D} \partial^{2} \mathrm{w}}{\mathrm{b}^{2} \partial \mathrm{Q}^{2}} \\
\mathrm{M}_{\mathrm{y}}=\frac{\partial}{\partial^{2} \mathrm{Q}}\left(\mathrm{B}_{0}+\mathrm{B}_{1} \mathrm{Q}+\mathrm{B}_{2} \mathrm{Q}^{2}+\mathrm{B}_{3} \mathrm{Q}^{3}+\mathrm{B}_{4} \mathrm{Q}^{4}\right) \frac{-\mathrm{D}}{\mathrm{b}^{2}} \\
\mathrm{M}_{\mathrm{y}}=\left(2 B_{2}+6 B_{3} \mathrm{Q}+12 B_{4} \mathrm{Q}^{2}\right) \frac{-\mathrm{D}}{\mathrm{b}^{2}}
\end{gathered}
$$

\section{(a) All Round Simply Supported Thin Rectangular Plate (SSSS)}

Figure 1 shows a thin rectangular with all edges $\mathrm{R}=0$, a; and $Q=0, b$ are simply supported.

The boundary conditions are: deflections and moments at all edges are zero, slope at all edges except $Q=b$ is zero.

With these conditions, we obtained displacement function as:

$$
\begin{aligned}
& W(x, y)=A_{4} B_{4}\left(R-2 R^{3}+R^{4}\right)\left(Q-2 Q^{3}+Q^{4}\right) \\
& W(x, y)=K\left(R-2 R^{3}+R^{4}\right)\left(Q-2 Q^{3}+Q^{4}\right)
\end{aligned}
$$

\section{(b) All Round Clamped Thin Rectangular Plate (CCCC)}

Figure 2 shows a rectangular with such edges such that $R=0,1$; and $Q=0,1$ are clamped.

The boundary conditions are: deflections at all edges are zero, slope at all edges is zero. With these conditions, we obtain displacement function as: 


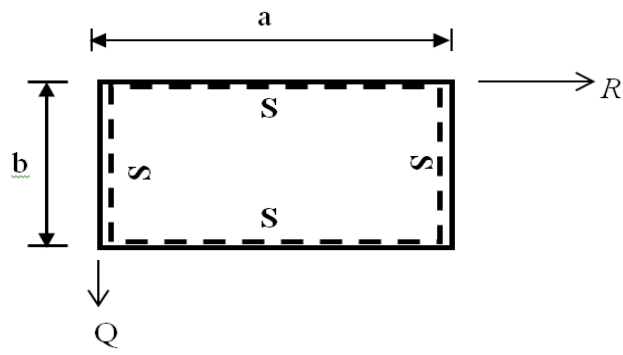

Figure 1: SSSS - Thin Rectangular Plate

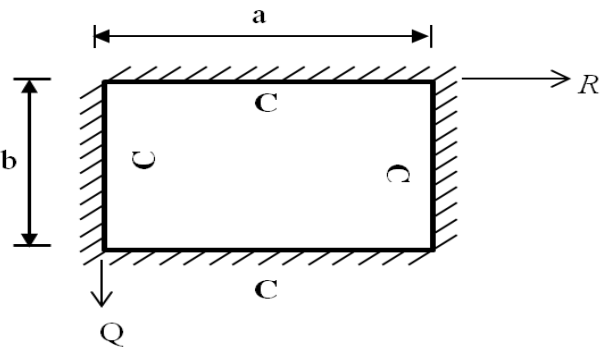

Figure 2: Rectangular Plate Clamped

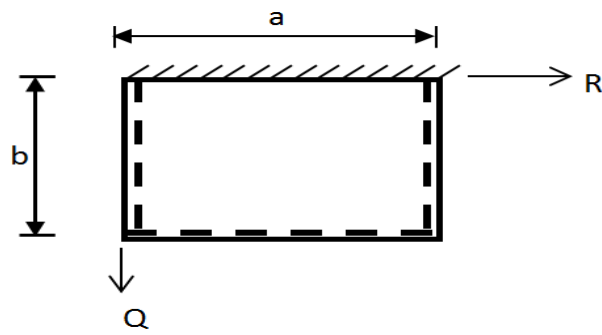

Figure 3: CSSS - Thin Rectangular Plate

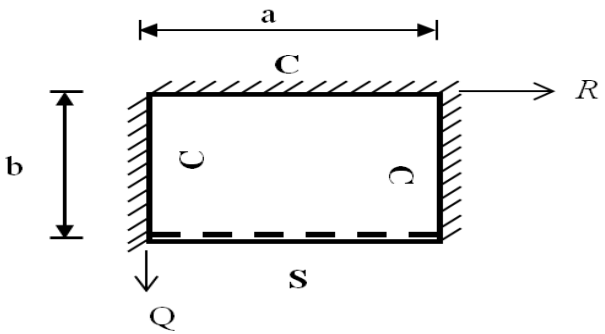

Figure 4: CCSC - Thin Rectangular Plate

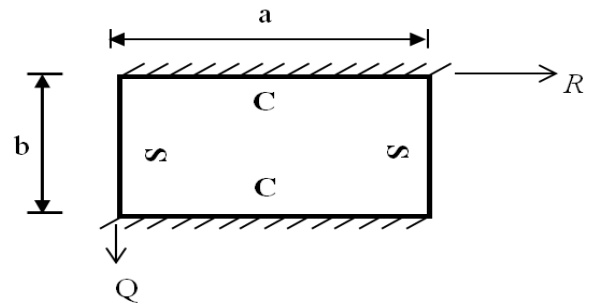

Figure 5: CSCS - Thin Rectangular

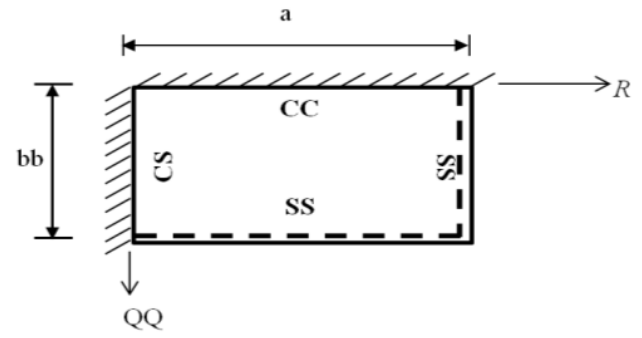

Figure 6: CCSS - Thin

$W(x, y)=A_{4} B_{4}\left(R^{2}-2 R^{3}+R^{4}\right)\left(Q^{2}-2 Q^{3}+Q^{4}\right)$

$W(x, y)=K\left(R^{2}-2 R^{3}+R^{4}\right)\left(Q^{2}-2 Q^{3}+Q^{4}\right)$ (c) Thin Rectangular Plate with One Edge Clamped and all Others Edges Simply Supported (CSSS)

The boundary conditions are: deflections at all edges are zero, slope at edge $(Q=0)$ is zero; Moment at all edges except $(Q=0)$ is zero.

With these conditions, we obtain displacement function as:

$$
\begin{gathered}
\mathrm{W}(\mathrm{R}, \mathrm{Q})=\mathrm{W}_{\mathrm{x}} \cdot \mathrm{W}_{\mathrm{y}} \\
=A_{4} B_{4}\left(\mathrm{R}-2 \mathrm{R}^{3}+\mathrm{R}^{4}\right)\left(1.5 Q^{2}-2.5 Q^{3}+Q^{4}\right) \\
W(R, Q)=K\left(R-2 R^{3}+R^{4}\right)\left(1.5 Q^{2}-2.5 Q^{3}+Q^{4}\right)
\end{gathered}
$$

\section{(d) Thin Rectangular Plate With One Edge Simply Supported and all Other Edges Clamped (CCSC)}

The boundary conditions are: deflections at all edges are zero, slope at all edges (except $Q=1$ ) is zero and Moment at $\mathrm{Q}=1$ is zero

We obtain displacement function as

$$
\begin{gathered}
\mathrm{W}(\mathrm{R}, \mathrm{Q})=\mathrm{W}_{\mathrm{x}} \cdot \mathrm{W}_{\mathrm{y}} \\
=A_{4} B_{4}\left(\mathrm{R}^{2}-2 \mathrm{R}^{3}+\mathrm{R}^{4}\right)\left(1.5 Q^{2}\right. \\
\left.-2.5 Q^{3}+Q^{4}\right) \\
\quad \text { where } K=A_{4} B_{4} \\
\therefore W(R, Q)=K\left(\mathrm{R}^{2}-2 \mathrm{R}^{3}+\mathrm{R}^{4}\right)\left(1.5 Q^{2}-2.5 Q^{3}\right. \\
\left.+Q^{4}\right)
\end{gathered}
$$

(e) Thin Rectangular Plate Simply Supported at Two Opposite Edges and Clamped on the Other Two (CSCS)

Figure 5 shows a thin rectangular plate simply supported at two opposite sides and clamped at the others. The boundary conditions are: deflections at all edges are zero, slope at edge $(\mathrm{Q}=0$ or $\mathrm{b})$ is zero, Moment at edge $(\mathrm{R}=0$ or $\mathrm{b}$ ) is zero. With these conditions, we obtain displacement function as:

$$
\begin{aligned}
& W(x, y)=A_{4} B_{4}\left(\mathrm{R}-2 \mathrm{R}^{3}+\mathrm{R}^{4}\right)\left(Q^{2}-2 Q^{3}+Q^{4}\right) \\
& W(x, y)=K\left(\mathrm{R}-2 \mathrm{R}^{3}+\mathrm{R}^{4}\right)\left(Q^{2}-2 Q^{3}+Q^{4}\right)
\end{aligned}
$$

(f) Thin Rectangular Plate Clamped at Two Adjacent Edges and Simply Supported at the Other Two (CCSS)

Figure 6 shows a thin rectangular plate clamped at two adjacent sides and simply supported at the others. The boundary conditions are: deflections at all edges are zero, slope at edges $(R=0 ; Q=0)$ are zero; Moment at edges $(R=a$, and $Q=b)$ are zero.

With these conditions, we obtain displacement function as:

$$
\begin{aligned}
& \mathrm{W}(\mathrm{R}, \mathrm{Q})=\mathrm{W}_{\mathrm{x}} \cdot \mathrm{W}_{\mathrm{y}} \\
& \quad=A_{4} B_{4}\left(1.5 R^{2}-2.5 R^{3}+R^{4}\right)(1.5 Q \\
& \left.\quad-2.5 Q^{3}+Q^{4}\right) \\
& \text { Where } \mathrm{K}=A_{4} \beta_{4} \\
& \quad W(R, Q)=K\left(1.5 R^{2}-2.5 R^{3}+R^{4}\right)\left(1.5 Q^{2}-2.5 Q^{3}+Q^{4}\right)
\end{aligned}
$$




\section{ANALYSIS OF FUNDAMENTAL NATURAL FREQUENCY EQUATIONS OF ORTHOTROPIC PLATES}

\subsection{SSSS - Thin Plates}

From Equation (32) the shape function for SSSS is given as:

$$
W=K\left(R-2 R^{3}+R^{4}\right)\left(Q-2 Q^{3}+Q^{4}\right)
$$

Putting Equation (43) into Equation (11) for a thin rectangular orthotropic plate under free vibration according to Galerkin's Method, we have:

$\omega^{2}=\frac{\iint_{A}^{g}\left(D_{x} \frac{\partial^{4} w}{a^{4} \partial R^{4}}+2 H \frac{\partial^{4} w}{a^{2} b^{2} \partial R^{2} \partial Q^{2}}+D_{y} \frac{\partial^{4} w}{b^{4} \partial Q^{4}}\right) \bar{W} d R d Q}{\iint_{A}^{g} \rho h[W(R, Q)] \bar{W} d R d Q}$

Solving the integrand we obtain

$$
\omega=\pi^{2} \sqrt{\frac{1}{\rho h}\left(\frac{1.0015 D_{x}}{a^{4}}+\frac{2.0008 H}{a^{2} b^{2}}+\frac{1.0015 D_{y}}{b^{4}}\right)}
$$

\subsection{CCCC Thin Plates}

From Equation (34), the shape function for CCCC is given as:

$$
W_{x}=K\left(R-2 R^{3}+R^{4}\right)\left(Q^{2}-2 Q^{3}+Q^{4}\right)
$$

Substituting Equation (46) in Equation (11) and solving the integrand give:

$$
\omega=\pi^{2} \sqrt{\frac{1}{\rho h}\left(\frac{5.1747}{a^{4}} D_{x}+\frac{2.9565}{a^{2} b^{2}} H+\frac{5.1747 D_{y}}{b^{4}}\right)}
$$

\subsection{CSSS Thin Plates}

From Equation (36), the shape function for CSSS is given as:

$W_{x}=K\left(R-2 R^{3}+R^{4}\right)\left(1.5 Q^{2}-2.5 Q^{3}+Q^{4}\right)$

Substituting Equation (48) in Equation (11) and solving the integrand give:

w

$$
=\pi^{2} \sqrt{\frac{1}{\rho h}\left(\frac{5.1747}{a^{4}} D_{x}+\frac{2.9565}{a^{2} b^{2}} H+\frac{5.1747 D_{y}}{b^{4}}\right)}
$$

\subsection{CCSC Thin Plate}

From Equation (38), the shape function for CCSC is given as:

$$
W_{x}=A\left(R^{2}-2 R^{3}+R^{4}\right)\left(1.5 Q^{2}-2.5 Q^{3}+Q^{4}\right)
$$

Substituting Equation (50) in Equation (11) and solving the integrand give:

$\omega=\pi^{2} \sqrt{\frac{1}{\rho h}\left(\frac{5.1725 \mathrm{D}_{\mathrm{x}}}{\mathrm{a}^{4}}+\frac{2.8050 H}{\mathrm{a}^{2} \mathrm{~b}^{2}}+\frac{2.4533 \mathrm{D}_{\mathrm{y}}}{\mathrm{b}^{4}}\right)}$

\subsection{CSCS Thin Plates}

From Equation (40), the shape function for CSCS is given as:

$$
W_{x}=A\left(R-2 R^{3}+R^{4}\right)\left(Q^{2}-2 Q^{3}+Q^{4}\right)
$$

Substituting Equation (52) in Equation (11) and solving the integrand give: $\omega=\pi^{2} \sqrt{\frac{1}{\rho h}\left(\frac{1.0016 D_{x}}{a^{4}}+\frac{2.4316 H}{a^{2} b^{2}}+\frac{5.1747 D_{y}}{b^{4}}\right)}$

\subsection{CCSS Thin Plates}

From Equation (42), the shape function for CCSS is given as:

$W_{x}=A\left(1.5 R-2.5 R^{3}+R^{4}\right)\left(Q^{2}-2.5 Q^{3}+Q^{4}\right)$

Substituting Equation (54) in Equation (11) and solving the integrand give:

$\omega=\pi^{2} \sqrt{\frac{1}{\rho h}\left(\frac{2.4506 D_{x}}{a^{4}}+\frac{2.6536 H}{a^{2} b^{2}}+\frac{2.4506 D_{y}}{b^{4}}\right)}$

\section{RESULTS}

In the preliminary design of a doubly reinforced concrete slab of arbitrary support conditions, the following physical and geometric properties are provided: $\mathrm{f}_{\mathrm{cu}}=$ $35 \mathrm{MPa} \mu_{\mathrm{c}}=0.20,12 \mathrm{~mm}$ diameter mild steel spaced $150 \mathrm{~mm}$ each ways at the top and bottom. Modulus of elasticity of steel, $E_{s}=205,000 \mathrm{~N} / \mathrm{mm}^{2}$ Thickness of slab, $\mathrm{h}=175 \mathrm{~mm}$, Density of reinforced concrete, $\rho=$ $2563 \mathrm{Kg} / \mathrm{m}^{3}=0.000002563 \mathrm{Kg} / \mathrm{mm}^{3}, \mathrm{a}=5000 \mathrm{~mm}$, for $\mathrm{b} / \mathrm{a}=0.5,0.6,0.7,0.8,0.9$ and 1.0 ; cover to all reinforcement, $\mathrm{c}=25 \mathrm{~mm}$.

It is required to determine the fundamental frequency of the slab.

\subsection{Solution}

The results are computed from Equations (45), (47), (49), (51), (53) and (55)

From Neville [10],

$$
E_{c}=4.73\left(f^{\prime}{ }_{c}\right)^{0.5}
$$

Where, $\mathrm{f}_{c}$ and $\mathrm{E}_{\mathrm{c}}$ are the characteristic strength and modulus of elasticity of the concrete respectively. Thus, the moment of inertia at the $\mathrm{X}$ and $\mathrm{y}$ directions are given as:

and

$$
I_{x s}=I_{x^{\prime} x^{\prime}}+A d^{2}
$$

$$
\mathrm{I}_{\mathrm{ys}}=\mathrm{I}_{\mathrm{y}^{\prime} \mathrm{y}^{\prime}}+\mathrm{Ad}^{2}
$$

where

$$
\mathrm{I}_{\mathrm{x}^{\prime} \mathrm{x}^{\prime}}=\mathrm{S}_{\mathrm{vx}} \frac{\pi \emptyset_{\mathrm{sy}}^{4}}{64}
$$

and

$$
\mathrm{I}_{\mathrm{y} \mathrm{y}^{\prime}}=\mathrm{S}_{\mathrm{vy}} \frac{\pi \emptyset_{\mathrm{sx}}^{4}}{64}
$$

But, $S_{v x}$ and $S_{v y}$ are the number of the reinforcements perpendicular to $\mathrm{x}$ and $\mathrm{y}$ directions respectively; $\emptyset_{\text {sy }}$ and $\emptyset_{\text {sx }}$ are diameters of steel in those directions respectively. $\mathrm{I}_{\mathrm{X}^{\prime} \mathrm{X}^{\prime}}=$ Moment of Inertia of an Area, for steel about an axis, $\mathrm{xx}$-axis, $\mathrm{I}_{\mathrm{y}^{\prime} \mathrm{y}^{\prime}}=$ Moment of Inertia of an Area, for steel about an axis, yy, $\mathrm{A}=$ Area of steel, $\mathrm{d}=$ centroid of $\mathrm{a}$ lamina about $\mathrm{xx}$ and $\mathrm{yy}$-axis respectively. $\mathrm{h}=$ centroid of a lamina about $\mathrm{xx}$ and yy axis. $\mathrm{I}_{\mathrm{xs}}$ and $\mathrm{I}_{\mathrm{ys}}$ are moment of 
inertia of steels bars about $\mathrm{x}$ and $\mathrm{y}$ directions respectively.

Tables 1, 2 and 3 show the results of the fundamental frequencies obtained for doubly reinforced sections or reinforced concrete slabs (orthotropic rectangular plates) respectively. The results of earlier works [8] were also obtained using the procedure developed in this work and are compared with the analytical results also obtained herein.

\section{DISCUSSION OF RESULTS}

In Table 1, the results of the fundamental natural frequencies for SSSS and CCCC plates for aspect ratios: $0.5 \leq b / a \leq 1.0$ from the literature and the present study are (12.082 - $5.170 \mathrm{rad} / \mathrm{sec}$ and $12.089-5.173$ $\mathrm{rad} / \mathrm{sec})$; and (23.955 - $9.430 \mathrm{rad} / \mathrm{sec}$ and 23.956 $9.430 \mathrm{rad} / \mathrm{sec}$ ) respectively. The differences are marginal: $0.05 \%$ and $0 \%$ for SSSS and CCCC plates respectively. This shows that the shape functions derived using this characteristic orthogonal polynomials approach is adequate.

For CSSS plate, the fundamental frequencies obtained for aspect ratios: $0.5 \leq \frac{b}{a} \leq 1.0$ ranges from $16.862 \mathrm{rad} / \mathrm{sec}$ $6.202 \mathrm{rad} / \mathrm{sec}$. whereas, the literature results for this range of aspect ratios are: $19.502 \mathrm{rad} / \mathrm{sec}-8.048$ $\mathrm{rad} / \mathrm{sec}$. The results of study differ from the literature values with an average difference of $19 \%$. However, a close observation of the natural frequency value for SSSS and CCCC for this range of aspect ratios in this presentation. Hence the results obtained herein are very reliable and gives a better application than earlier works as found in the literature.
The CSSS plate that has three edges simply supported and one edge fixed is expected to have natural frequency values that are a little over those of SSSS plate and values lesser than those of the CCCC plate. This scenario is demonstrated with the present formulation results in Table 2 . Hence, the present results are very reliable over the literature results.

Table 3 give the values of natural frequencies for CCSC, CSCS, and CCSS plates for aspect ratios: $0.5 \leq b / a \leq 1.0$. No available studies for these plates have been carried out earlier.

\section{CONCLUSIONS}

The conclusion from this study is summarized below:

(a) Fundamental natural frequency of plates varies with the plate's edge conditions. Clamped edges of plate tend to give higher frequency and stiffness, as well as very small period of oscillation, while simply supported edges possess lower frequency and stiffness with marginal high period of oscillation.

(b) SSSS, CSSS, CSCS, CCSS, CCSC and CCCC plates are in the ascending order of plates' frequency and stiffness.

(c) The characteristic orthogonal polynomial based derived shape functions for rectangular plates are satisfactory in approximating the deformed shape of thin rectangular plates of various boundary conditions.

(d) An indirect variation principle (based on Galerkin's method) can be used in confidence to satisfactorily analyze real time rectangular thin plates of various boundary conditions under in- plane loadings.

Table 1: Fundamental Natural Frequenciesw of SSSS and CCCC Thin Rectangular Orthotropic Plates

\begin{tabular}{cccccc} 
& \multicolumn{2}{c}{ Simply Supported all round (SSS) $\omega(\mathrm{rad} / \mathrm{sec})$} & \multicolumn{2}{c}{ all round Clamped Plate (CCCC) $\omega(\mathrm{rad} / \mathrm{sec})$} \\
\hline b/a & Leissa [1969] & Present Study & \% Diff & Leissa [1969] & Present Study \\
\hline 0.5 & 12.082294 & 12.089119 & 0.06 & 23.955080 & 23.956242 \\
0.6 & 9.294095 & 9.299012 & 0.05 & 17.853305 & 17.854125 \\
0.7 & 7.596308 & 7.600141 & 0.05 & 14.241131 & 14.241764 \\
0.8 & 6.504117 & 6.507281 & 0.05 & 11.999870 & 12.000374 \\
0.9 & 5.729505 & 5.732241 & 0.05 & 10.476999 & 10.477434 \\
1.0 & 5.170286 & 5.172742 & 0.05 & 9.429502 & 0.08 \\
\hline
\end{tabular}

Table 2 Fundamental Natural Frequencies of CSSS Thin Rectangular Orthotropic Plate Different support condition (CSSS)

\begin{tabular}{cccc}
\multicolumn{4}{c}{ Different support condition (CSSS) } \\
$\omega(\mathrm{rad} / \mathrm{sec})$ \\
\hline $\mathrm{b} / \mathrm{a}$ & Leissa [1969] & Present Study & $\%$ Diff \\
0.5 & 19.502173 & 16.861613 & -13.54 \\
0.6 & 14.998937 & 12.528553 & -16.47 \\
0.7 & 12.204807 & 9.903814 & -18.85 \\
0.8 & 10.368122 & 8.226532 & -20.66 \\
0.9 & 9.034632 & 7.046468 & -22.01 \\
1.0 & 8.047780 & 6.202358 & -22.93 \\
\hline
\end{tabular}

Table 3: Fundamental Natural Frequencies of CCSC, CSCS and CCSS Thin Rectangular Orthotropic Plates

\begin{tabular}{llll}
\hline b/a & $\begin{array}{l}\text { CCSC } \\
\omega(\mathrm{rad} / \mathrm{sec}) \\
\text { Present } \\
\text { Study }\end{array}$ & $\begin{array}{l}\text { CSCS } \omega(\mathrm{rad} / \mathrm{sec}) \\
\text { Present Study }\end{array}$ & $\begin{array}{l}\text { CCSS } \\
\omega(\mathrm{rad} / \mathrm{sec}) \\
\text { Present Study }\end{array}$ \\
\hline 0.5 & 18.019769 & 23.088498 & 17.394250 \\
0.6 & 13.915458 & 16.785503 & 13.141580 \\
0.7 & 11.511431 & 12.957086 & 10.596813 \\
0.8 & 10.033191 & 10.525836 & 8.994340 \\
0.9 & 9.034668 & 8.809916 & 7.885202 \\
1.0 & 8.041400 & 6.272057 & 7.105523 \\
\hline
\end{tabular}




\section{RECOMMENDATIONS}

The following recommendations are made based on this study:

(a) The fundamental natural frequencies formulated in this study for SSSS, CSSS, CSCS, CCSS, CCSC and CCCC plates should be adopted for the structural design of these plates.

(b) Future research work should consider applying Rayleigh - Ritz direct variational method to the shape functions formulated in this study for SSSS, CSSS, CSCS, CCSS, CCSC and CCCC plates.

(c) Future studies can employ the shape function presented herein and the Galerkin's method to analyze plate.

(d) Future studies should use the shape function used herein and Galerkin's method to analyze plate on elastic foundation.

(e) It is suggested that further work in this area should consider the application of the characteristic orthogonal polynomials to analyze plates on other boundary conditions such as free ends.

\section{REFERENCES}

[1] Izumi, M., .Impact and Dynamic Load Effects, Proceedings of International Conference on Planning and Design of Tall Buildings, Vol. 1B, pp 77 - 83. 1972.

[2] Euler, L. De motuvibratoriotympanorum, Novi Comrnentari Acad Petropolit, vol.10, pp.243-260. 1766.

[3] Ventsel, E., and Krauthammer, Thin Plates and Shells: Theory, Analysis and Applications, Maxwell Publishers Inc; New York. 2001.
[4] Thompson, W. T., and Dahleh, M. D. Theory of Vibration with Applications, $5^{\text {th }}$ edition, Dorling Kindersley (India) Pvt. Ltd, New Delhi. 2007.

[5] Xiang, Y., Liew, K. M., and Kitipornchai, S. Vibration Analysis of Rectangular Mindlin Plates Resting on Elastic Edge Supports. Journal of Sound and Vibration, vol. 204, pp. 1-16. 1997.

[6] Gorman, D. J. Accurate Free Vibration Analysis of Shear-deformable Plates with Torsional Elastic Edge Support. Journal of Sound and Vibration, vol. 203, pp 209-218. 1997.

[7] Malaikah, A. K., Al-saif and Al-zaid, R. .Prediction of the Dynamic Modulus of Elasticity of Concrete under Different Loading Conditions, International Conference on Concrete Engineering and Technology, Universiti Malaya. (http://faculty.ksu.edu.sa/malaikah/papers/predic tiction\%20of\%20the \%20Dynamic\%20Modulus $\% 2$ 0of\%Elasticity.pdf). 2004.

[8] Leissa, A.W. Vibration of Plates, National Aeronautics and Space Administration, Washington D.C. 1969.

[9] Dym, C. L., and Williams, H. E. .Estimating Fundamental Frequencies of Tall Building. Journal of Structural Engineering, ASCE, Vol. 133, No. 10. 2007.

[10] Neville, A. M. Properties of concrete (4th Ed.). London: Dorling Kindersley Ltd. 2006.

[11] Chakraverty, S. Development of characteristic orthogonal polynomials (Cops): In vibration problems of plates. Boca Raton: CRC Press. 2009.

[12] Timoshenko, S. P., and Woinowsky - Krieger, S. . Theory of plates and shells (2nd ed.). Auckland: McGraw-Hill Inc. 1970. 